\title{
Association between perception of caring behaviors and self-efficacy in patients with cardiovascular disease at coronary care units: a cross-sectional study
}

\author{
Leila Kargar', Zahra Khademian', Masoume Rambod ${ }^{2}$ \\ ${ }^{1}$ Department of Nursing, School of Nursing and Midwifery, Shiraz University of Medical Sciences, Shiraz; ${ }^{2}$ Community Based Psychiatric Care Research \\ Center, Department of Nursing, School of Nursing and Midwifery, Shiraz University of Medical Sciences, Shiraz, Iran
}

Background: Assessing and improving patient self-efficacy are among the major roles of nurses. Nurses are also responsible for providing direct patient care, and they play a major role in improving patient care quality. Therefore, it is essential to evaluate nurses' care-giving behaviors. This study aimed to determine the association between caring behaviors and selfefficacy in patients with cardiovascular disease.

Methods: In this cross-sectional study, 400 patients with cardiovascular disease who were admitted to hospitals in Jahrom, southern Iran, were selected through a stratified sampling. The Caring Behaviors Inventory and the Strategies Used by People to Promote Health questionnaires were used to collect data. Data were analyzed using descriptive statistics, Kolmogorov-Smirnov test and Spearman correlation coefficient in SPSS ver. 22.

Results: Results showed significant relationships between perception of caring behaviors and self-efficacy $(r=0.16, P=0.001)$ as well as subscales of respectful deference to others $(r=0.12$, $P=0.01)$, assurance of human presence $(r=0.12, P=0.02)$, and positive connectedness $(r=0.18$, $\mathrm{P}=0.001$ ). Additionally, among the subscales of caring behaviors, "attentive to others' experience," with a mean of $5.17 \pm 1.10$, was the highest priority and "positive connectedness," with a mean of $4.81 \pm 1.31$, was the lowest priority for patients. The mean self-efficacy score was $73.94 \pm 29.78$, and 169 patients (43.2\%) had low self-efficacy.

Conclusions: Given the positive relationship between perception of caring behaviors and self-efficacy in patients with cardiovascular disease, self-efficacy could be improved by paying more attention to patient care priorities and improving patient perception of caring behaviors.

Key Words: cardiovascular disease; empathy; intensive care unit; nurses; nurse-patient relations; self-efficacy

\section{INTRODUCTION}

Cardiovascular diseases are a main cause of death globally. The prevalence of cardiovascular diseases has doubled from 271 million in 1990 to 523 million in 2019, and mortality caused by these diseases increased from 12.1 million to 18.6 million [1]. In Iran, cardiovascular diseases are increasing and are the main cause of $46 \%$ of mortalities and account for $20 \%-23 \%$ of disease burden [2]. Given the high prevalence and burden of cardiovascular disease, it is

\section{Original Article}

Received: September 16, 2020

Revised: February 20, 2021

Accepted: March 16, 2021

Corresponding author

Zahra Khademian

Department of Nursing, Fatemeh

(PBUH) School of Nursing and

Midwifery, Namazi Square, Zand

Street, Shiraz 71936-13119, Iran

Tel: $+98-7136474254$

Fax: +98-71136474252

E-mail:zahrakhademian@yahoo.com

Copyright (๑) 2021 The Korean Society of Critical Care Medicine

This is an Open Access article distributed under the terms of Creative Attributions Non-Commercial License (https:// creativecommons.org/li-censes/by-nc/4.0/) which permits unrestricted noncommercial use, distribution, and reproduction in any medium, provided the original work is properly cited. 
important to seek solutions to help patient healing and reduce disease complications [3]. Improving quality of care and treatment through patient participation in healthcare programs can improve patients' physical condition and, hence, reduce mortality and cost $[4,5]$. Empowering patients with cardiovascular diseases to engage in self-care could help control disease symptoms and prevent or delay disease complications [6]. One empowerment strategy is to improve self-efficacy [7].

Self-efficacy is defined as a person's belief in their ability to perform in a certain situation, and as a person's belief in their ability to adapt to particular situations [8]. Cardiac self-efficacy is also defined as a patient's confidence in their ability to manage the conditions posed by their cardiac disease [9]. Cardiac self-efficacy is considered a marker of heart function [10]. Higher cardiac self-efficacy was found to predict better cardiac function and self-rated mental and physical health. It was also associated with a reduced likelihood of hospital readmission $[10,11]$. Self-efficacy was indicated to be of particular importance for managing cardiovascular disease because improvement in a patient's outcomes is largely dependent on whether they engage in self-management activities, lifestyle modification, and risk-factor control. Self-efficacy encourages patients with cardiovascular disease to take an active role in self-management activities and adopt a healthy lifestyle [12]. On the other hand, low self-efficacy was associated with poor quality of life among patients with coronary heart disease [13]. Therefore, improving cardiac self-efficacy is one of the critical outcomes of healthcare services $[10,11,13]$.

Bandura [8] argues that patient self-efficacy and empowerment can increase under suitable conditions where patients can acquire skills and knowledge to succeed. Nurses are responsible for provisioning direct patient care and, as such, they play an important role in providing a safe and high-quality care in critical care setting [14]. They also actively help patients acquire the knowledge and skills required to adapt to conditions posed by the diseases. Previous studies have shown improved self-efficacy among patients with chronic disease after receiving nurse-led educational interventions $[15,16]$. Given the role of nurses in improving patient self-efficacy, it is possible that nursing care is associated with patient self-efficacy.

Caring is the essence of nursing, and nurses demonstrate their roles and activities through caring behaviors $[17,18]$. Caring behaviors include the knowledge, skills, attitudes, and values necessary for professional therapeutic interactions [17], such as alleviating patient discomfort and anticipating and

\section{KEY MESSAGES}

- We found a small association between perception of caring behaviors and self-efficacy in patients with cardiovascular diseases.

- The mean score of perception of caring behaviors was high. - "Attentive to other's experience" was the most and "positive connectedness" was the least important subscale of caring behaviors.

- The mean score of self-efficacy in patients with cardiovascular diseases was moderate, and self-efficacy was low in $43.2 \%$ of the patients.

meeting physical and emotional needs [18-20]. Wolf et al. [21] identified five dimensions of caring behaviors: assurance of human presence, positive connectedness, attentive to others' experience, professional knowledge and skills, and respectful deference to others. It is thought that a nurse's caring approach has a role in patient wellbeing and health promotion $[18,22]$. Therefore, it is necessary to identify which nurses' caring behaviors are associated with improved patient self-efficacy.

Several studies showed that patients with cardiovascular disease had low $[10,23]$ to moderate [24] cardiac self-efficacy. Therefore, evaluation of cardiac self-efficacy and its associated factors is needed to help patients manage their lives better and for healthcare systems to arrange effective secondary cardiac rehabilitation when needed $[10,11,25]$. Previous studies identified some factors associated with self-efficacy, including age, gender, occupation, body mass index, health behaviors, awareness of risk factors, heart disease diagnosis, history of receiving patient education, and perception and knowledge of disease [26,27]. The perceptions of patients with cardiovascular disease regarding their experience was associated with self-efficacy [27]. However, there is insufficient evidence to link patient perceptions of nurse caring behaviors to their selfefficacy. Understanding the association between these variables allows for prioritization of caring behaviors in patients with different levels of self-efficacy and tailoring caring plans according to patient needs. In other words, knowing which nursing care behaviors are related to higher patient self-efficacy helps nurses encourage patients to adopt these behaviors. We hypothesized that nurse activities with regard to caring behaviors is associated with patient self-efficacy. Therefore, herein, we aimed to evaluate the association between caring behaviors and self-efficacy in patients with cardiovascular diseases. 


\section{MATERIALS AND METHODS}

\section{Ethical Considerations}

This study was approved by the Ethics Committee of Shiraz University of Medical Sciences (IR.SUMS.REC.1397.418) and hospital authorities. Patients provided informed consent and were assured of the right to withdraw from the study and to keep their personal information confidential.

\section{Design and Participants}

This cross-sectional study recruited patients admitted to the coronary care units of two hospitals (Peymaniyeh Hospital and Motahari Hospital) in Jahrom, southern Iran, from October 2018 to March 2019. According to Cochran's formula and a correlation coefficient $r=0.50, \alpha=0.05$, and $\beta=0.80$, a sample size of 384 was required. Given expectations of sample attrition, a sample of 400 patients was recruited.

The study sample was stratified so that the number of subjects from each hospital unit was proportional to the number of patients in the unit. Then the eligible patients who were willing to participate to the study were selected until the sample size was completed. The inclusion criteria were adults 18 years and over, medical diagnosis of myocardial infarction, unstable angina pectoris, or heart failure, at least a 3-day stay in the cardiac care unit, awareness of time, place, and person, and the ability to understand study questions. The exclusion criteria were disabling diseases other than heart disease and underlying diseases such as sleep disorders, known mental disorders, Alzheimer disease, adverse events within the prior 6 months, such as death of a loved one or divorce, and inability to complete the questionnaires. At study termination, nine patients were excluded due to incomplete questionnaires. Finally, data from 391 patients were analyzed.

\section{Data Collection and Measurements}

The Caring Behaviors Inventory (CBI) and Strategies Used by People to Promote Health (SUPPH_29) questionnaires were used to collect data. Demographic information included gender, age, history of hospitalization and length of stay, other illnesses, marital status, education, and medical diagnosis. The CBI was developed by Wolf [28] in 1981 and included 75 items. In 1994 Wolf et al. [21] reduced the CBI to 42 items. CBI-42 measures patients' perception of caring behaviors with five subscales including respectful deference to others, assurance of human presence, positive connectedness, professional knowledge and skill, and attentive to others' experience. Respectful deference to others implies nurses' respectful behav- ior when providing care to the patients. Assurance of human presence invokes the caring behaviors of nurses that create a feeling of encouragement, confidence, and reassurance in patients and the ability to reduce patient anxiety. Positive connectedness is the feeling of solidarity, empathy, and unity between the patient and the nurse that manifests during patient care. Professional knowledge and skill explicitly reflect a nurse's experience and technical abilities when proving care. Atten-

Table 1. Distribution of demographic and clinical data of patients with cardiovascular disease

\begin{tabular}{|c|c|}
\hline Variable & No. $(\%)(n=391)$ \\
\hline \multicolumn{2}{|l|}{ Sex } \\
\hline Male & $221(56.5)$ \\
\hline Female & $170(43.5)$ \\
\hline \multicolumn{2}{|l|}{ Marital status } \\
\hline Single & $36(9.2)$ \\
\hline Married & $245(62.7)$ \\
\hline Widowed & 99 (25.3) \\
\hline Divorced & $11(2.8)$ \\
\hline \multicolumn{2}{|l|}{ Education } \\
\hline Non-literate & $140(35.8)$ \\
\hline Junior high school & $132(33.8)$ \\
\hline Diploma & $86(22.0)$ \\
\hline Academic & $33(8.4)$ \\
\hline \multicolumn{2}{|l|}{ Employment } \\
\hline Employed & 156 (39.9) \\
\hline Retired & $142(36.3)$ \\
\hline Unemployed & 91 (23.3) \\
\hline Housewife & $2(0.5)$ \\
\hline \multicolumn{2}{|l|}{ Place of residence } \\
\hline City & $236(60.4)$ \\
\hline Village & $155(39.6)$ \\
\hline \multicolumn{2}{|l|}{ Diagnosis } \\
\hline Heart failure & $190(47.5)$ \\
\hline Myocardial infarction & $150(37.5)$ \\
\hline Unstable angina pectoris & $60(15)$ \\
\hline \multicolumn{2}{|l|}{ Length of stay (day) } \\
\hline 3 & $227(58.1)$ \\
\hline 4 & $85(21.7)$ \\
\hline$\geq 5$ & 79 (20.2) \\
\hline \multicolumn{2}{|l|}{ Frequency of admission } \\
\hline 1 & $186(47.6)$ \\
\hline 2 & $175(44.8)$ \\
\hline$\geq 3$ & $30(7.6)$ \\
\hline
\end{tabular}


tive to others' experience evaluates a nurse's attention and care for patients and to meet their needs through listening and observing. Each item is scored on a 6-point Likert scale from "never" (1) to "always" (6). The minimum score for this inventory is 42 and the maximum is 252 . Higher scores indicate more important caring behaviors according to patients $[21,28]$. In this study, given the different number of items for each subscale, to make the subscales comparable, the score for each subscale was divided into the number of questions for that subscale, and the mean weighted score was obtained. Wolf et al. [21,29] confirmed the validity of the inventory using exploratory factor analysis with varimax rotation and its reliability with a Cronbach's coefficient (0.96) and test-retest reliability (0.96). Hajinezhad et al. [30] confirmed the content validity of the Persian version using the opinions of ten nursing faculty members. Reliability of the inventory for patients was also found to be internally consistent according to Cronbach's coefficient $(\mathrm{r}=0.98)$.

The SUPPH-29 questionnaire was developed by Lev and Owen [31] in 1996 to measure self-efficacy among patients with cancer. Afterward, it was used for other health conditions such as hypertension [23], hemodialysis [32], and ulcerative colitis [15]. This questionnaire has three domains: stress reduction (10 items), making decisions ( 3 items), and positive attitude (3 items) and is based on a 5-point Likert scale from very low (1), low (2), moderate (3), high (4), and very high (5). Total possible scores range from 29 to 145 . Scores over 90 indicate high self-efficacy, 67-90 indicate moderate self-efficacy, and $<67$ indicate low self-efficacy [31]. Lev and Owen [31] confirmed instrument construct validity using exploratory factor analysis. They also confirmed its reliability by test-retest $(r=0.94)$. To confirm the validity of the Persian version of the instrument, Moattari et al. [32] translated it into Persian and then English. Content validity of the Persian version of this instrument was confirmed by an expert panel and its reliability was confirmed by Cronbach's alpha coefficient of 0.91. Data were collected after explaining the objectives to patients and obtaining their consent. Interviews were conducted when the patients had neither pain nor elevated anxiety and were wellprepared to answer the questions.

\section{Data Analysis}

The data were analyzed using IBM SPSS ver. 22 (IBM Corp., Armonk, NY, USA). Descriptive statistics were used to describe the variables. The Kolmogorov-Smirnov test evaluated data normality and the Spearman correlation coefficient was used to examine the relationship between perception of caring behaviors and self-efficacy. The significance level was set to $\mathrm{P}=0.05$.

\section{RESULTS}

The mean patient age was $54.15 \pm 15.77$ years (range, $20-80$ years). Most patients were male $(\mathrm{n}=221,56.5 \%)$, married ( $\mathrm{n}=$ $245,62.7 \%)$, employed ( $n=156,39.9 \%)$, city dwellers $(n=236$, $60.4 \%$ ) with a diploma or less ( $\mathrm{n}=358,91.6 \%)$. Additionally, they were admitted for heart failure $(\mathrm{n}=190,47.5 \%)$, myocardial infarction $(n=150,37.5 \%)$, or unstable angina pectoris $(\mathrm{n}=60,15 \%)$. Most had been admitted to hospital for the first time $(\mathrm{n}=186,47.6 \%)$ and the length of stay was 3 days for most $(\mathrm{n}=227,58.1 \%)$ (Table 1$)$.

The mean self-efficacy score among patients with cardiovascular disease was $73.94 \pm 29.78$, and self-efficacy was low in 43.2\% ( $\mathrm{n}=169)$, moderate in $28.6 \%(\mathrm{n}=112)$, and high in $28.1 \%(n=110)$ of patients. Table 2 shows that according to the patients, "attentive to others' experiences" was the most important and "positive connectedness" was the least important subscale of perception of caring behaviors. Additionally, there was a significant direct relationship between self-efficacy and total perception of caring behaviors score $(\mathrm{r}=0.16, \mathrm{P}=0.001)$ and between self-efficacy and several subscale measures, in-

Table 2. Mean patient perception scores for caring behavior subscales and their relationship with patient self-efficacy

\begin{tabular}{lccc}
\hline Subscale & Weighted mean \pm weighted SD & Range & ${\text { Association with self-efficacy } r(P \text {-value })^{b}}^{\text {a }}$ \\
\hline Attentive to others' experience & $5.17 \pm 1.10$ & $1.25-6$ & $0.02(0.46)$ \\
Respectful deference to others & $5.08 \pm 0.98$ & $1.50-6$ & $0.12(0.01)$ \\
Professional knowledge and skills & $5.06 \pm 1.26$ & $1-6$ & $0.09(0.08)$ \\
Assurance of human presence & $4.96 \pm 1.21$ & $1-6$ & $0.12(0.02)$ \\
Positive connectedness & $4.81 \pm 1.31$ & $1-6$ & $0.18(0.001)$ \\
Total score of perception of caring behaviors & $4.99 \pm 1$ & $1.50-6$ & $0.16(0.001)$ \\
\hline
\end{tabular}

SD: standard deviation.

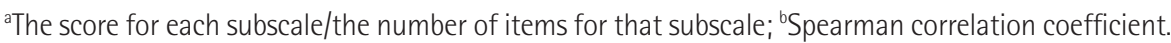


Table 3. Mean patient self-efficacy domain scores and their relationship with patient perception of caring behaviors

\begin{tabular}{lccc}
\hline \multirow{2}{*}{$\begin{array}{c}\text { Self-efficacy } \\
\text { domain }\end{array}$} & $\begin{array}{c}\text { Possible } \\
\text { range of } \\
\text { scores }\end{array}$ & Mean \pm SD & $\begin{array}{c}\text { Total score of percep- } \\
\text { tion of caring behaviors }\end{array}$ \\
\cline { 4 - 4 } Stress reduction & $10-50$ & $23.42 \pm 10.29$ & $0.15(0.003)$ \\
Decision making & $3-15$ & $7.77 \pm 3.7$ & $0.15(0.003)$ \\
Positive attitude & $16-80$ & $42.86 \pm 17.78$ & $0.14(0.006)$ \\
Self-efficacy & $29-145$ & $73.94 \pm 29.78$ & $0.16(0.001)$ \\
\hline
\end{tabular}

SD: standard deviation.

aSpearman correlation coefficient.

cluding respectful deference to others $(\mathrm{r}=0.12, \mathrm{P}=0.01)$, assurance of human presence $(\mathrm{r}=0.12, \mathrm{P}=0.02)$, and positive connectedness $(\mathrm{r}=0.18, \mathrm{P}=0.001)$. Spearman correlation coefficient results indicate that the total score for perception of caring behaviors was significantly correlated with self-efficacy domains (Table 3).

\section{DISCUSSION}

This study evaluated the association between caring behaviors and self-efficacy in patients with cardiovascular diseases, including heart failure, myocardial infarction, and unstable angina pectoris. Results showed a significant relationship between self-efficacy and total score for perception of caring behaviors, including respectful deference to others, assurance of human presence, and positive connectedness.

The existence of a relationship, even a small one, between perception of caring behaviors and patient self-efficacy allows nurses to adopt appropriate caring behaviors to help their cardiovascular disease patients improve their self-efficacy. Given the important role of self-efficacy in adopting a healthy lifestyle and managing cardiovascular disease, these findings are enlightening [12,25]. The relationship between assurance of human presence and self-efficacy indicates that nurses could improve patient self-efficacy by assuring them, being by their side, and talking to them. Furthermore, the positive relationship between positive connectedness and self-efficacy implies that paying attention to patients and making physical touch in accordance with their culture, giving hope and empathy, and being kind and welcoming, could improve individual patient mastery, i.e., self-efficacy for healthy lifestyle habits. The relationship between respectful deference to others and self-efficacy indicates that respectful behavior of nurses can improve their self-efficacy [28].

In general, the association between self-efficacy and per- ception of caring behaviors was poor. Patients' perception of caring behaviors had a high mean score, while the self-efficacy of most patients was low, which may explain the poor correlation between these two factors. A literature review revealed no studies on the association between perception of caring behaviors and patient self-efficacy, thus, no comparisons to our study are possible. Therefore, more similar studies in different contexts are needed. It seems that providing caring with respect, appropriate communication, and reassurance of presence, especially for first-time admitted patients, could be a critical step in promoting self-efficacy.

The mean score for perception of caring behaviors in patients with cardiovascular diseases was high, indicating that patients participating in the study showed concern for all caring behaviors, even though some behaviors were identified as more important than others. According to patients, "attentive to others' experience," "respectful deference to others," "professional knowledge and skills," "assurance of human presence," and "positive connectedness" are, consecutively ordered, the most important caring behaviors.

Behaviors related to "attentive to others' experience" were endorsed as the most important caring behaviors. This shows that paying special attention to admitted patients is important to relieve their unpleasant feelings. Other studies have similarly attached great importance to provision of appropriate physical care, such as medication and patient physical control $[33,34]$. In another Iranian study, patients emphasized "monitoring and follow-up" as one of their top priorities [35]. Nurses are responsible for direct care of patients and should prioritize their time to provide that care [36]. In this study, a large number of the patients were admitted for the first time. Patients face a great deal of stress upon hospital admission. Therefore, nurses should understand their condition and pay special attention to it. Additionally, this issue may be important because patients are most concerned with the physical aspects of their care [19]. In this study, nurses' professional knowledge and skills were of specific importance, which is consistent with findings by Papastavrou et al. [37], whose review study showed that cancer patients placed higher importance on nurses' technical skills and experience.

On the other hand, although mean scores for "positive connectedness" and "assurance of human presence" were high, patients rated them less important than the other subscales. These findings are consistent with Karlou et al. [33] and AziziFini et al. [17]. In contrast to this study, Pashaee et al. [19] and Zamanzadeh et al. [35] found that nurse accessibility was patients' highest priority. This may be because the nurse-to-pa- 
tient ratio is higher in coronary care units and, because of the nature of the disease and ward conditions, nurses are more likely to interact with patients. Additionally, because of these patients' special needs, nurses spend more time at the bedside and the presence of nurses is more prominent in these departments. Therefore, they gave less priority to behaviors related to nurses' communication and presence.

Although the mean self-efficacy score for patients in this study was moderate, almost half the patients did not demonstrate proper self-efficacy. Consistent with these results, two other Iranian studies showed that patients with cardiovascular diseases and hypertension did not have high self-efficacy and performed self-care behaviors poorly $[23,38]$. Another study found that self-efficacy of patients after coronary artery bypass graft was moderate [24]. In contrast to this study, two other studies found that patients diagnosed with heart disease showed high capability and self-efficacy $[7,39]$. These different findings could be due to differences in culture, perception, and beliefs among the study populations. Additionally, Peyman et al. [38] identified education as an important factor affecting poor self-efficacy in patients with cardiovascular disease. Therefore, low education attainment may contribute to low self-efficacy in this study. Accordingly, it is necessary to seek effective strategies to enhance patients' self-efficacy, especially using inclusive approaches, such as innovative technologies [40].

This is the first study to examine the relationship between self-efficacy in cardiovascular disease patients and their perception of caring behaviors. The findings herein, such as the role of caring behaviors in enhancing patient self-efficacy, could be useful in promoting nurses' performance in clinical settings. These findings could also contribute to training in nursing schools and in-service nursing programs. However, because patient perception of the importance of caring behaviors does not reflect the extent to which nurses present these behaviors, future studies that investigate the relationship between self-efficacy of patients and the rate of caring behaviors presented by nurses are needed. Furthermore, the association between caring behaviors and self-efficacy was small. Therefore, we recommend caution when applying these findings in a clinical setting. We argue that this weak relationship could be related to the patients' low self-efficacy. Therefore, further studies to investigate this relationship over a longer period, in which patients have sufficient time to improve their self-efficacy, are also recommended.

\section{CONFLICT OF INTEREST}

No potential conflict of interest relevant to this article was reported.

\section{ACKNOWLEDGMENTS}

This study was extracted from a master's thesis by Leila Kargar and was supported by the Vice-Chancellor for Research and Technology of Shiraz University of Medical Sciences (grant No. 16696). The authors are grateful to the Clinical Research Development Center of Namazi Hospital and Dr. Marjan Faghih, who contributed to the statistical analyses of this study. The authors are also grateful to the authorities of Peymaniyeh and Motahari Hospitals in Jahrom, and to the patients who participated in the study.

\section{ORCID}

Leila Kargar https://orcid.org/0000-0001-8540-356X

Zahra Khademian https://orcid.org/0000-0001-8366-204X Masoume Rambod https://orcid.org/0000-0002-7334-9364

\section{AUTHOR CONTRIBUTIONS}

Conceptualization: all authors. Data curation: LK. Formal analysis: ZK, LK. Funding acquisition: ZK. Methodology: all authors. Project administration: LK. Visualization: all authors. Writing-original draft: LK, ZK. Writing-review \& editing: all authors.

\section{REFERENCES}

1. Roth GA, Mensah GA, Johnson CO, Addolorato G, Ammirati E, Baddour LM, et al. Global burden of cardiovascular diseases and risk factors, 1990-2019: update from the GBD 2019 study. J Am Coll Cardiol 2020;76:2982-3021.

2. Sarrafzadegan N, Mohammmadifard N. Cardiovascular disease in Iran in the last 40 years: prevalence, mortality, morbidity, challenges and strategies for cardiovascular prevention. Arch Iran Med 2019;22:204-10.

3. Zahra P, Maryam JM, Foroozan AS, Alireza AB. Assessing patient adherence to treatment after coronary artery bypass graft. J Sabzevar Univ Med Sci 2015;22:668-75.

4. Ghadirian F, Vahedian-Azimi A, Ebadi A. Value-based care and the necessity of economic evaluation of nursing services. J Hayat 2018;24:197-203. 
5. Javanmardifard S, Heidari S, Sanjari M, Yazdanmehr M, Shirazi F. The relationship between spiritual well-being and hope, and adherence to treatment regimen in patients with diabetes. J Diabetes Metab Disord 2020;19:941-50.

6. Riegel B, Moser DK, Buck HG, Dickson VV, Dunbar SB, Lee $\mathrm{CS}$, et al. Self-care for the prevention and management of cardiovascular disease and stroke: a scientific statement for healthcare professionals from the American Heart Association. J Am Heart Assoc 2017;6:e006997.

7. A study of self-efficacy in patients with coronary artery disease and its predictors. Qom Univ Med Sci J 2013;7:41-8.

8. Bandura A. Self-efficacy in changing societies. Cambridge: Cambridge University Press; 1995.

9. Fors A, Ulin K, Cliffordson C, Ekman I, Brink E. The cardiac self-efficacy scale, a useful tool with potential to evaluate person-centred care. Eur J Cardiovasc Nurs 2015;14:536-43.

10. Sarkar U, Ali S, Whooley MA. Self-efficacy as a marker of cardiac function and predictor of heart failure hospitalization and mortality in patients with stable coronary heart disease: findings from the Heart and Soul Study. Health Psychol 2009; 28:166-73.

11. O’Neil A, Berk M, Davis J, Stafford L. Cardiac-self efficacy predicts adverse outcomes in coronary artery disease (CAD) patients. Health 2013;5:6-14.

12. Guo P, Harris R. The effectiveness and experience of self-management following acute coronary syndrome: a review of the literature. Int J Nurs Stud 2016;61:29-51.

13. Barham A, Ibraheem R, Zyoud SH. Cardiac self-efficacy and quality of life in patients with coronary heart disease: a crosssectional study from Palestine. BMC Cardiovasc Disord 2019; 19:290.

14. Farmani Z, Kargar M, Khademian Z, Paydar S, Zare N. The effect of training and awareness of subtle control on the frequency of hand hygiene among intensive care unit nurses. BMC Res Notes 2019;12:647.

15. Magharei M, Jaafari S, Mansouri P, Safarpour A, Taghavi SA. Effects of self-management education on self-efficacy and quality of life in patients with ulcerative colitis: a randomized controlled clinical trial. Int J Community Based Nurs Midwifery 2019;7:32-42.

16. Baljani E, Salimi S, Rahimi J, Amanpour E, Parkhashjou M, Sharifnejad A, et al. The effect of education on promoting self efficacy in patients with cardiovascular disease. J Kermanshah Univ Med Sci 2012;16:e78799.

17. Azizi-Fini I, Mousavi MS, Mazroui-Sabdani A, Adib-Hajbaghery M. Correlation between nurses' caring behaviors and patients' satisfaction. Nurs Midwifery Stud 2012;1:36-40.
18. Khademian Z, Vizeshfar F. Nursing students' perceptions of the importance of caring behaviors. J Adv Nurs 2008;61:45662.

19. Pashaee S, Lakdizaji S, Rahmani A, Zamanzadeh V. Priorities of caring behaviors from critical care nurses viewpoints. Prev Care Nurs Midwifery J 2014;4:65-73.

20. Blasdell ND. The meaning of caring in nursing practice. Int J Nurs Clin Pract 2017;4:238.

21. Wolf ZR, Giardino ER, Osborne PA, Ambrose MS. Dimensions of nurse caring. Image J Nurs Sch 1994;26:107-11.

22. Watson J. Unitary caring science: philosophy and praxis of nursing. Colorado: University Press of Colorado; 2018.

23. Khademian Z, Kazemi Ara F, Gholamzadeh S. The effect of self care education based on Orem's nursing theory on quality of life and self-efficacy in patients with hypertension: a quasiexperimental study. Int J Community Based Nurs Midwifery 2020;8:140-9.

24. Salimian S, Esmaieli R, Dabirian A, Mansoorin S, Anboohi SZ. The survey of factors related to self-efficacy based on Orem's theory in patients with coronary artery bypass surgery in Tehran in 2014. Adv Nurs Midwifery 2016;25:9-16.

25. Salari A, Balasi LR, Moaddab F, Zaersabet F, Saeed AN, Nejad SH. Patients' cardiac self-efficacy after coronary artery angioplasty. Jundishapur J Chronic Dis Care 2016;5:e60308.

26. Shrestha R, Rawal L, Bajracharya R, Ghimire A. Predictors of cardiac self-efficacy among patients diagnosed with coronary artery disease in tertiary hospitals in Nepal. J Public Health Res 2020;9:1787.

27. Kang Y, Yang IS. Cardiac self-efficacy and its predictors in patients with coronary artery diseases. J Clin Nurs 2013;22:246573.

28. Wolf, ZR. The concept of caring: beginning exploration. Candidacy paper. Philadelphia: University of Pennsylvania School of Nursing; 1981.

29. Wolf ZR, Miller PA, Devine M. Relationship between nurse caring and patient satisfaction in patients undergoing invasive cardiac procedures. Medsurg Nurs 2003;12:391-6.

30. Hajinezhad ME, Azodi P, Rafii F, Ramezanian N, Tarighat M. Perspectives of patients and nurses on caring behaviors of nurses. J Hayat 2012;17:36-45.

31. Lev EL, Owen SV. A measure of self-care self-efficacy. Res Nurs Health 1996;19:421-9.

32. Moattari M, Ebrahimi M, Sharifi N, Rouzbeh J. The effect of empowerment on the self-efficacy, quality of life and clinical and laboratory indicators of patients treated with hemodialysis: a randomized controlled trial. Health Qual Life Outcomes 2012;10:115. 
33. Karlou C, Papathanassoglou E, Patiraki E. Caring behaviours in cancer care in Greece: comparison of patients', their caregivers' and nurses' perceptions. Eur J Oncol Nurs 2015;19:24450.

34. Compton EK, Gildemeyer K, Reich RR, Mason TM. Perceptions of caring behaviours: a comparison of surgical oncology nurses and patients. J Clin Nurs 2019;28:1680-4.

35. Zamanzadeh V, Azimzadeh R, Rahmani A, Valizadeh L. Oncology patients' and professional nurses' perceptions of important nurse caring behaviors. BMC Nurs 2010;9:10.

36. Valizadeh L, Zamanzadeh V, Azimzadeh R, Rahmani A. The view of nurses toward prioritizing the caring behaviors in cancer patients. J Caring Sci 2012;1:11-6.

37. Papastavrou E, Efstathiou G, Charalambous A. Nurses' and patients' perceptions of caring behaviours: quantitative systematic review of comparative studies. J Adv Nurs 2011;67: 1191-205.

38. Peyman N, Abdollahi M, Zadeh Ahmad Z. The study of related factors with self-care and self-efficacy in heart failure patients. J Torbat Heydariyeh Univ Med Sci 2018;6:55-61.

39. Kärner Köhler A, Tingström P, Jaarsma T, Nilsson S. Patient empowerment and general self-efficacy in patients with coronary heart disease: a cross-sectional study. BMC Fam Pract 2018;19:76.

40. Khademian F, Aslani A, Bastani P. The effects of mobile apps on stress, anxiety, and depression: overview of systematic reviews. Int J Technol Assess Health Care 2020;37:e4. 